\title{
PERMANENT PREVALENCE OF NOSEMA CERANAE IN HONEY BEES (APIS MELLIFERA) IN HUNGARY
}

\author{
Tamás CSÁKI ${ }^{1 *}$, Miklós HeLTAI ${ }^{1}$, Ferenc MARKOLT ${ }^{1}$, Balázs KovÁCS ${ }^{2}$, László BÉKÉSI ${ }^{3}$, \\ Márta LADÁNYI ${ }^{4}$, Erika PÉNTEK-ZAKAR ${ }^{5}$, Aránzazu MEANA ${ }^{6}$, Cristina BotíAs ${ }^{7}$, \\ Raquel MARTíN-HERNÁNDEZ ${ }^{7}$ and Mariano HIGES ${ }^{7}$ \\ ${ }^{1}$ Institute for Wildlife Conservation, Szent István University, Páter K. u. 1, \\ H-2013 Gödöllő, Hungary; ${ }^{2}$ Regional University Center of Excellence in Environmental \\ Industry, Szent István University, Gödöllő, Hungary; ${ }^{3}$ Research Centre for Farm Animal \\ Gene Conservation, Institute for Apiculture, Hungary; ${ }^{4}$ Corvinus University of Budapest, \\ Budapest, Hungary; ${ }^{5}$ University of Debrecen, Debrecen, Hungary; ${ }^{6}$ Department of \\ Animal Health, Faculty of Veterinary, Complutense University of Madrid, Madrid, \\ Spain; ${ }^{7}$ Bee Pathology Laboratory, Centro Apícola Regional, Consejería de Agricultura, \\ Junta de Comunidades de Castilla-La Mancha, Marchamalo, Spain
}

(Received 18 November 2014; accepted 22 June 2015)

Nosema ceranae is present in honey bee (Apis mellifera L.) colonies worldwide. Studies on the comparative virulence of $N$. ceranae and $N$. apis showed significant differences in individual mortality, and the prevalence of $N$. ceranae seems to be predominant in both the continental and the Mediterranean climate regions. This study attempted to monitor the geographical and seasonal distribution of these two Nosema species in Hungary, using a simple laboratory method. The distribution of $N$. ceranae and $N$. apis infection rates along all seasons was homogeneous $(\mathrm{P}=0.57)$. In co-infected samples, the intensity of $N$. ceranae infection was always significantly higher than that of $N$. apis infection $(\mathrm{P}<0.001)$. The infection rate of infected bees in exterior samples was higher than in interior samples in each season; however, the differences were not statistically significant. The species $N$. ceranae had been present in Hungary already in 2004. Statistical analysis of data shows that the infection level is best represented by sampling exterior bees to establish the proportion of infected bees rather than by determining the mean spore count.

Key words: Honey bee, nosemosis, Nosema ceranae, spore count, multiplex PCR

Nosema disease in honey bees is caused by two types of microsporidian parasites, Nosema apis (Zander, 1909) and Nosema ceranae (Higes et al., 2006), and it is a significant economic issue worldwide (Botías et al., 2013; Goblirsch et al., 2013; Higes et al., 2013). Nosema ceranae had been described as a parasite of the Asian bee (Apis ceranae) in the late 1990s (Fries, 1997); however, one

\footnotetext{
"Corresponding author; E-mail: csaki.tamas@gmail.com
} 
decade later it was detected in A. mellifera (Higes et al., 2006) and soon thereafter it was reported as the predominant microsporidium infecting honey bees in many countries (Martín-Hernández et al., 2007, 2011; Botías et al., 2012). Colonies affected by $N$. apis generally display latent infection during summer, a small peak in autumn, and a slow increase of infection during winter (Bailey, 1955). Nosema ceranae can be detected in samples throughout the year, even in the summer months, as there is no evidence of seasonality under certain climatic conditions (Martín-Hernández et al., 2007). The presence of $N$. ceranae was first reported in Hungary by Tapaszti et al. (2009) in 2007 in 37 out of 38 Nosemainfected bee samples collected from Hungarian apiaries using PCR-RFLP methods. All of these 37 samples contained only N. ceranae, which indicated the dominance of $N$. ceranae in Hungarian apiaries.

Using the hypothesis that $N$. ceranae dominance over $N$. apis may prevail in all four seasons in Hungary, a monitoring research was designed to investigate the distribution of the two different Nosema spp. The prevalence of $N$. ceranae in Western Europe was observed in historical samples of honey bees (Chauzat et al., 2007) and honey (Botías et al., 2012) as far back as 2000, which may indicate that $N$. ceranae had also been present in Hungary at that time. Correct identification of the two Nosema species is the key to the study and control of nosema disease (nosemosis) of honey bees. Fingler et al. (1982) found a correlation between the percentage of infected bees and the average spore count of the sample as a whole. The mean spore count per bee has traditionally been used to determine the extent of colony infection (Furgala and Hyser, 1969) and was later developed to indicate the presence of $N$. apis infection. The mean spore count of $N$. ceranae was found not to be directly related to the infection level of the whole colony under field conditions (Higes et al., 2008; Meana et al., 2010). The spores produced by the two Nosema species are quite similar and can rarely be distinguished using traditional light microscopy. Genetic typing has to be used to characterise infections or co-infections by these two pathogens (Fries, 1997).

The first purpose of present study was to detect the presence of $N$. ceranae in Hungarian honey bee colonies prior to the 2007 samples collected by Tapaszti et al. (2009). The second purpose was to propose investigation of the distribution of the two different Nosema spp. throughout the year and determine the existence and levels of infections in interior and exterior bees. Another objective was to determine the spore count and the proportion of infected bees to quantify the degree of Nosema spp. infections for a detailed statistical analysis. A significant part of the work was carried out at the Spanish Laboratory of Bee Pathology (CAR = Centro Apícola Regional) in Marchamalo, Spain, but the final objective of the project was to adapt the methods of molecular genetic identification of Nosema species in our laboratory (RET $=$ Regional University Center of Excellence in Environmental Industry) at Szent István University in Gödöllö, Hungary. 


\section{Materials and methods}

\section{Sampling}

Nationwide sampling campaigns of live adult honey bees (Apis mellifera carnica P.) were organised during the spring (April), summer (July) and autumn (October) of 2010 across Hungary. To have a representative assessment of the scope of $N$. apis and $N$. ceranae prevalence, 44 apiaries were involved in the sampling campaigns representing all main geographical regions of the country (Fig. 2). Three colonies were randomly sampled in each apiary. Two types of samples were collected from each colony. Interior house bees were collected from the side frames that do not contain uncapped brood. To collect the exterior returning forager bees, entrances were closed for a 20 -min period. The forager bees were collected after they had settled in front of the blocked entrances. Sampling of a minimum of 60 individual bees was performed before 9 a.m. or after 3 p.m. to avoid collecting young bees during their exploratory flight.

\section{Historical sampling}

Stored samples from the Research Centre for Farm Animal Gene Conservation were taken, where a total of 26 samples of adult worker bees were stored from the year 2004. These samples had been collected from weak colonies and contained 10 to 20 adult bees per sample. The samples represented 11 out of 20 counties in Hungary.

\section{Sample processing at the Centro Apicola Regional (CAR), Marchamalo, Spain}

Spring and summer samples from the year 2010 were processed in the laboratory at the CAR in Spain. A total of 30 adult bees from each sample were macerated with $5 \mathrm{ml}$ molecular biology grade $\mathrm{H}_{2} \mathrm{O}$ (MilliQ system) for $2 \mathrm{~min}$ at high speed in a Stomacher 80 Biomaster (Seward, West Sussex, UK) using strainer bags (BA6040/STR, Seward). The filtered macerates were recovered in $15-\mathrm{ml}$ tubes and centrifuged for $6 \mathrm{~min}$ at $800 \times \mathrm{g}$. The supernatant was discarded and the final pellet resuspended in $1 \mathrm{ml}$ of $\mathrm{H}_{2} \mathrm{O}$. Each sample was visually checked by phase contrast microscope to verify the presence of Nosema sp. spores (OIE, 2008). To determine the presence of Nosema species, PCR analysis of the resuspended pellets was also performed using the methods previously described (Martín-Hernández et al., 2007; Botías et al., 2012). The sensitivity level of this technique is 2.5 spores of $N$. ceranae or 25 spores of $N$. apis in $150 \mu 1$ of bee macerate (CAR Laboratory, unpublished data). 


\section{Sample processing at the RET (Szent István University, Gödöllö, Hungary)}

The samples from October 2010 together with the Hungarian historical samples were processed in the laboratory of RET in Hungary. Sample processing at the CAR was carried out using 96-well microtitre plates. A total of 30 adult bees from each sample were macerated manually with $5 \mathrm{ml}$ molecular biology grade water $\left(\mathrm{H}_{2} \mathrm{O}\right)$ in individual LPDE zip lock bags (M6080B, Labsystem) for the PCR until the material became homogeneous. This process took at least 1 min per bag. The macerates were filtered through a disposable plastic net and recovered in $15-\mathrm{ml}$ tubes for centrifugation at $800 \times g$ for $6 \mathrm{~min}$. The supernatant was discarded and the pellet was resuspended in $1 \mathrm{ml}$ of $\mathrm{H}_{2} \mathrm{O}$. Each sample was than visually checked under a light microscope to verify the presence of Nosema sp. spores (OIE, 2008). The $1-\mathrm{ml}$ suspensions were centrifuged for $15 \mathrm{~min}$ at maximum rpm at $4{ }^{\circ} \mathrm{C}$ in $1.5-\mathrm{ml}$ Eppendorf tubes, then the supernatant was removed. Three hundred $\mu 1$ of CTAB buffer (Cornman et al., 2009) and $200 \mathrm{mg}$ of glass beads (425-600 mm, Sigma-Aldrich) were added. The tubes were taped to the shaker part of a vortex mixer (ZX3m, Velp Scientific) and vortexed with maximum rpm for $5 \mathrm{~min}$. Using this method we were able to process 10 tubes at one time. After the addition of $1000 \mathrm{mg}$ proteinase $\mathrm{K}$, the suspensions were incubated overnight $(12 \mathrm{~h})$ at $56^{\circ} \mathrm{C}$ with continuous shaking $(200 \mathrm{rpm})$. DNA was extracted using four cycles of centrifugation at $13,000 \mathrm{rpm}$ for $15 \mathrm{~min}$ at $4{ }^{\circ} \mathrm{C}$ with the supernatants $(300 \mu \mathrm{l})$ transferred to new tubes between cycles: first cycle with equal volumes of suspension and phenol $(1: 1)$, second cycle with equal volumes of supernatant, phenol and chloroform $(1: 1: 1)$, third cycle with equal volumes of supernatant and chloroform, and fourth cycle with 1:2.5 volumes of supernatant and cold $\left(-20^{\circ} \mathrm{C}\right)$ ethanol. After 2 min the pelleted DNA was collected by centrifugation (at $13,000 \mathrm{rpm}$ for $15 \mathrm{~min}$ at $4{ }^{\circ} \mathrm{C}$ ). The ethanol was discarded, the pellet was dried and $30 \mu \mathrm{l}$ of $\mathrm{H}_{2} \mathrm{O}$ was added. The extracted DNA was stored at $-20{ }^{\circ} \mathrm{C}$ until used. Quantity, quality and purity of DNA were analysed spectrophotometrically with Implen Nanophotometer (Implen $\mathrm{GmbH}$, Germany) and the concentration was adjusted to $20 \mathrm{ng} / \mu \mathrm{l}$ by water. The extracted DNA was analysed by PCR to determine the presence of Nosema sp. using the specific 218MITOC F/R and 321APIS F/R primers as described previously (Martín-Hernández et al., 2007). As positive control, COI-F and COI-R primers were used (Botías et al., 2012). The PCR reaction mix components were as follow, in $25 \mu \mathrm{l}$ containing $1 \times$ AmpliTaq Gold Polymerase buffer (Applied Biosystems), $1.5 \mathrm{mmol}$ of $\mathrm{MgCl}, 2 \mu \mathrm{Mol}$ of dNTP $2.5 \mathrm{BSA}(200 \mathrm{mg} / \mathrm{ml}), 3.3 \mu 1$ Triton $\mathrm{X}-100,1 \mathrm{U}$ AmpliTaq Gold DNA Polymerase (Applied Biosystems), $0.9 \mu \mathrm{M}$ of each pair of 218MITOC and 321APIS primers, $0.2 \mu \mathrm{M}$ of COI-F/R primers, and $9 \mu \mathrm{l}$ of DNA template. The thermocycler program was the same as described by Botías et al. (2012). Each PCR product was analysed by agarose electrophoresis (SeaKem LE-Lonsa) (Fig. 1). In order to detect possible contamination and to assess the reliability of sample processes between the two laboratories, the same 
negative and positive controls were processed in parallel during the extraction and PCR phases of analysis. Also, the leftovers of a total of 100 samples from the year 2010 (the original macerates and the leftovers of adult bees) processed at the CAR from spring were reprocessed at the RET.

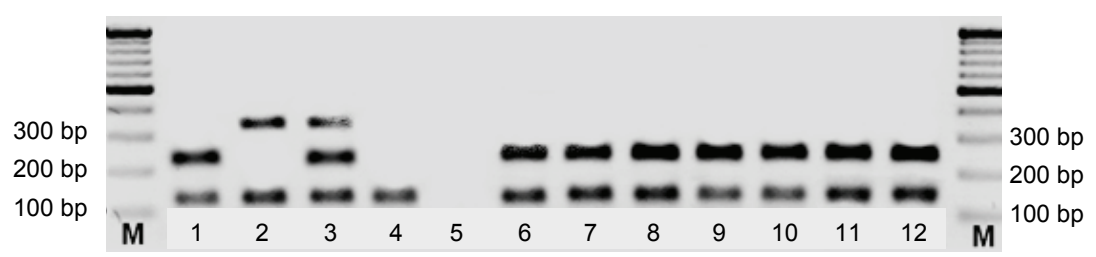

Fig. 1. Amplicons of different lengths, specific for the detection of Nosema ceranae, Nosema apis and Apis mellifera from multiplex PCR using the three pairs of primers (218MITOC F/R, 321APIS

F/R, COI-F and COI-R). Lane 1 shows positive control sample from A. mellifera infected with $N$.

ceranae, lane 2 shows positive control sample from $A$. mellifera infected with $N$. apis, lane 3

shows positive control sample from $A$. mellifera infected with both Nosema species, lane 4 shows positive control sample from A. mellifera without infection of the two types, lane 5 shows negative control sample without bee DNA, lanes 6 to 12 show the actual samples from the collection in the year 2010, and lane M is a 100 bp DNA ladder

\section{Spore counts and proportions of infected bees}

Mean spore counts were calculated using the previously macerated samples collected in autumn (October) of 2010 using the method of Cantwell (1970). A separate count to determine the proportion of infected bees per hive was calculated using the leftovers $(\mathrm{n}=30)$ of each autumn 2010 sample. The individual bees were macerated with $1 \mathrm{ml} \mathrm{H}_{2} \mathrm{O}$ and checked for spore presence under a light microscope. To determine a negative result for Nosema, multiple visualisations were performed on each sample from triple view focusing on different parts of the samples. A sample was declared to be not infected if no spores were detected in any of the three microscopic views.

\section{Statistical analysis}

Z-test was conducted to compare the independent probabilities. To test the homogeneity of distributions, Chi-square test was used. Linear quantile regression using MS Excel was used to calculate the connection between the mean spore count and the rate of infected bees and to calculate the extent of infection.

\section{Results}

A less expensive DNA isolation method and multiplex PCR analysis were used to detect and identify the two Nosema species in Hungarian honey bee colonies. Genetic typing identified Nosema sp. even in those samples in which light microscopy did not confirm infection. 


\section{Microscopic versus PCR identification}

Results of the microscopic evaluation of samples from 2010 were supported by the findings of PCR analysis. Data obtained from phase contrast microscopy are comparable to those found by light microscopy. Table 1 shows slightly higher infection rate using PCR than with either form of microscopy: $89 \%$ positivity rate with microscopy versus $95 \%$ with PCR on spring samples, $97 \%$ positivity with microscopy versus $98 \%$ PCR on summer samples, $95 \%$ positivity with microscopy versus $97 \%$ PCR on autumn samples, respectively. However, according to the Z-test, there were no significant differences between the infection rates detected by microscopy and PCR in any season $(\mathrm{P}>0.05)$.

Table 1

\begin{tabular}{lcc}
\multicolumn{3}{c}{ Comparison of the sensitivity of methods for Nosema sp. infectio } \\
\hline Season & Method & Positive samples (\%) \\
\hline \multirow{2}{*}{ Spring } & Microscopy & 89 \\
& PCR & 95 \\
Summer & Microscopy & 97 \\
& PCR & 98 \\
Autumn & Microscopy & 95 \\
& PCR & 97 \\
\hline
\end{tabular}

\section{Seasonal and geographical distribution of Nosema sp. during the study}

Using the data from 2010, the number of infected hives checked from season to season showed no significant difference (Z-test: $\mathrm{P}>0.05$ ). As shown in Table 2, the percentage of hives infected with Nosema sp. ranged between $95 \%$ and $98 \%$. The distribution of $N$. ceranae and $N$. apis infection rates along the seasons was homogeneous (Chi-square test: $\mathrm{P}=0.57$ ). The prevalence of $N$. ceranae was always significantly higher than that of $N$. apis and of co-infection (Z-test: P < 0.001). The rate of N. ceranae ranged from $95 \%$ to $98 \%$ in the infected samples (Fig. 2).

\section{Exterior and interior samples}

Regression analysis shows significant correlation between the mean spore count of the sample as a whole percentage of infected bees, and the percentage of infected bees per sample $\left(R_{\text {int }}=0.65\right.$ with $n=130 ; R_{\text {ext }}=0.43$ with $n=138 ; P<$ 0.001 in both cases). The infection rate of the infected bees in the exterior samples (Table 3) was higher than in the interior samples in each season; however, no significant differences were detected $\left(Z\right.$-test: $\mathrm{P}_{\text {spring }}=0.14 ; \mathrm{P}_{\text {summer }}=0.08 ; \mathrm{P}_{\text {autumn }}=$ $0.28)$. 
Table 2

Percentage of infected hives checked from different seasons

\begin{tabular}{lcccc}
\hline \multirow{2}{*}{ Season } & \multirow{2}{*}{$\begin{array}{c}\text { Rate of the } \\
\text { infected hives (\%) }\end{array}$} & Nosema ceranae (\%) & Nosema apis (\%) & Co-infection (\%) \\
\cline { 3 - 5 } & 95 & 95 & 1 & 4 \\
Spring & 98 & 97 & 0 & 3 \\
Summer & 97 & 98 & 1 & 1 \\
Autumn & & & & 4 \\
\hline
\end{tabular}

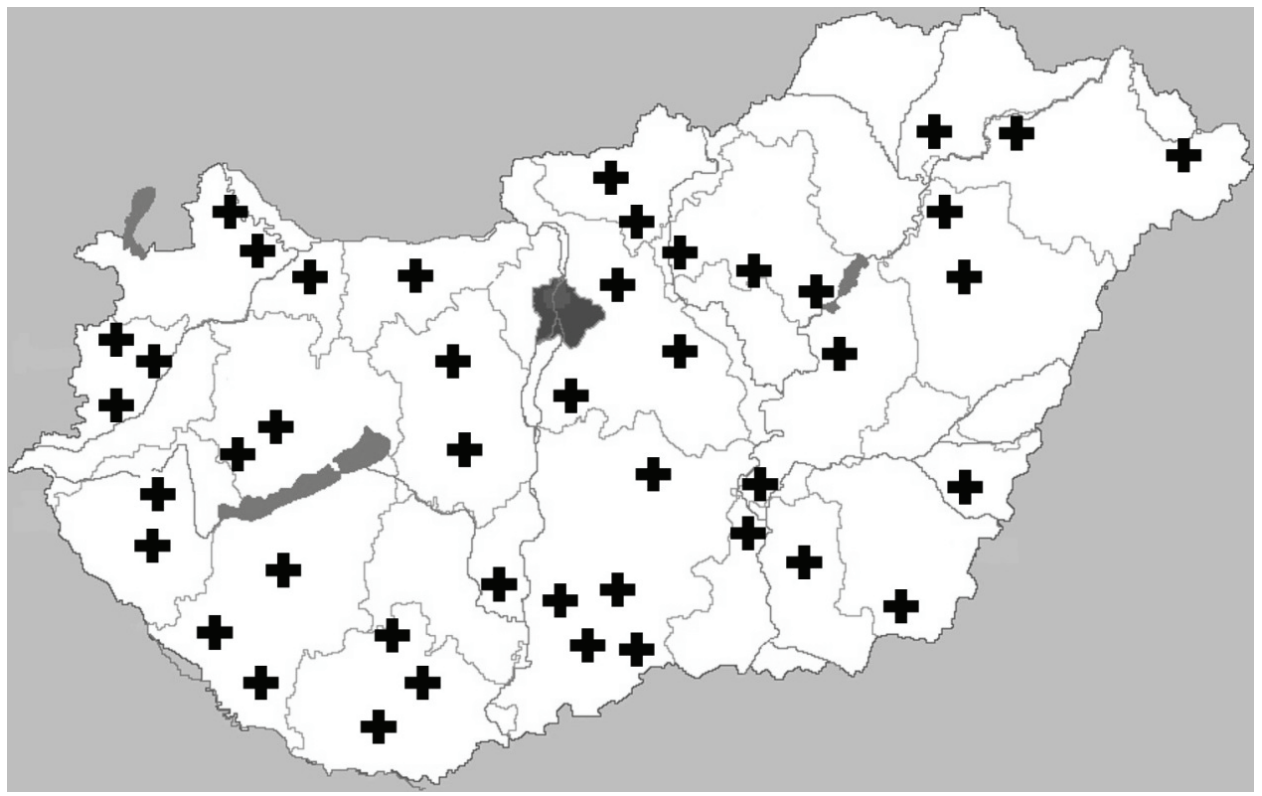

Fig. 2. The distribution of Hungarian sampling locations where Nosema ceranae infection of the samples was confirmed

\section{Table 3}

The rate of infected bees in exterior and interior samples in different seasons

\begin{tabular}{lcc}
\hline \multirow{2}{*}{ Season } & \multicolumn{2}{c}{ Sample type } \\
\cline { 2 - 3 } & Exterior (\%) & Interior (\%) \\
\hline Spring & 90 & 84 \\
Summer & 98 & 95 \\
Autumn & 94 & 90 \\
\hline
\end{tabular}


Quantile regression of the rate of infected bees depending on the mean spore count

First we defined the amount of mean spore count as low $(+)$, moderate $(++)$ or high $(+++)$, and calculated the quantiles of the mean proportion of infected bees $(5 \%, 10 \%, 50 \%, 90 \%$ and $95 \%$, respectively) (Table 4). A linear model was fitted to each quantile.

Table 4

Definition of spore count levels

\begin{tabular}{rccl}
\hline \multicolumn{4}{c}{ Mean spore count (thousands) } \\
\hline Exterior & Interior & Mean spore count rate \\
\hline $0-24.99$ & $0-9.99$ & + & Low \\
$25-49.99$ & $10-24.99$ & ++ & Moderate \\
$50-160$ & $25-100$ & +++ & High \\
\hline
\end{tabular}

According to our qualification system, a colony is at a high risk (HR) if more than $50 \%$ of the population is infected (Higes et al., 2008, 2013; Botías et al., 2012). A moderate risk (MR) exists when less than 50\% but more than $30 \%$ of the population is infected. Infection rates below $30 \%$ mean a low risk (LR) of infection (Table 5). By risk we mean the appearance of colony weakening and reduction in population on colony level.

Table 5

Definition of the rate of risk depending on the rate of infection

\begin{tabular}{cc}
\hline Rate of infection (\%) & Extent of risk \\
\hline$<30$ & Low risk \\
$30-50$ & Moderate risk \\
$50<$ & High risk \\
\hline
\end{tabular}

Figure 3 shows that the probability of low risk (less than $30 \%$ of the interior population infected) is more than 0.9 , and in this case the mean spore count is below 10,000. If the spore count is between 10,000 and 25,000, the population has a low risk of infection with a probability of about 0.5 . If the spore count is above 25,000 , the population has a moderate or high risk with a probability of more than 0.9.

Figure 4 illustrates that the exterior population can have a high risk (more than $50 \%$ of the population infected) with a probability of about 0.5 even in those cases where the mean spore count is below 25,000. If the spore count is between 25,000 and 50,000, the population has high or moderate risk of infection 
with a probability of about 0.9 . If the spore count is above 50,000 , the population has high or moderate risk of infection with a probability of more than 0.95 .

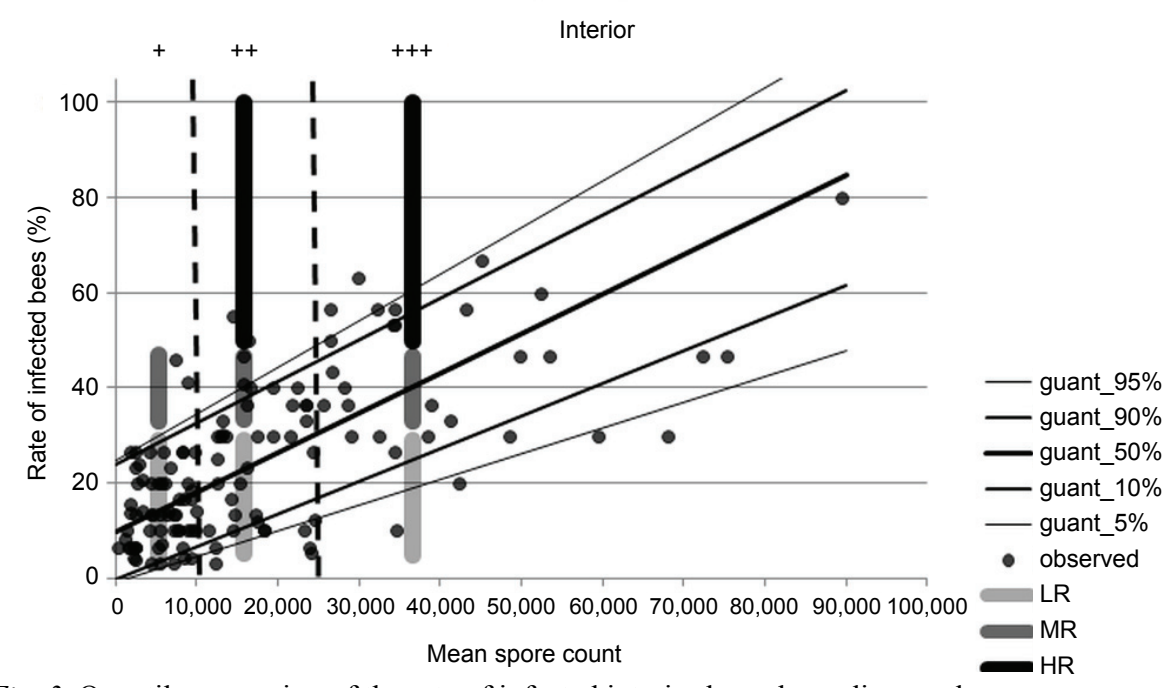

Fig. 3. Quantile regression of the rate of infected interior bees depending on the mean spore count with the rate of spore amount $[$ low $(+)$, moderate $(++)$ and high $(+++)]$ and with the extent of infection risk [high risk (HR), moderate risk (MR) or low risk (LR)]

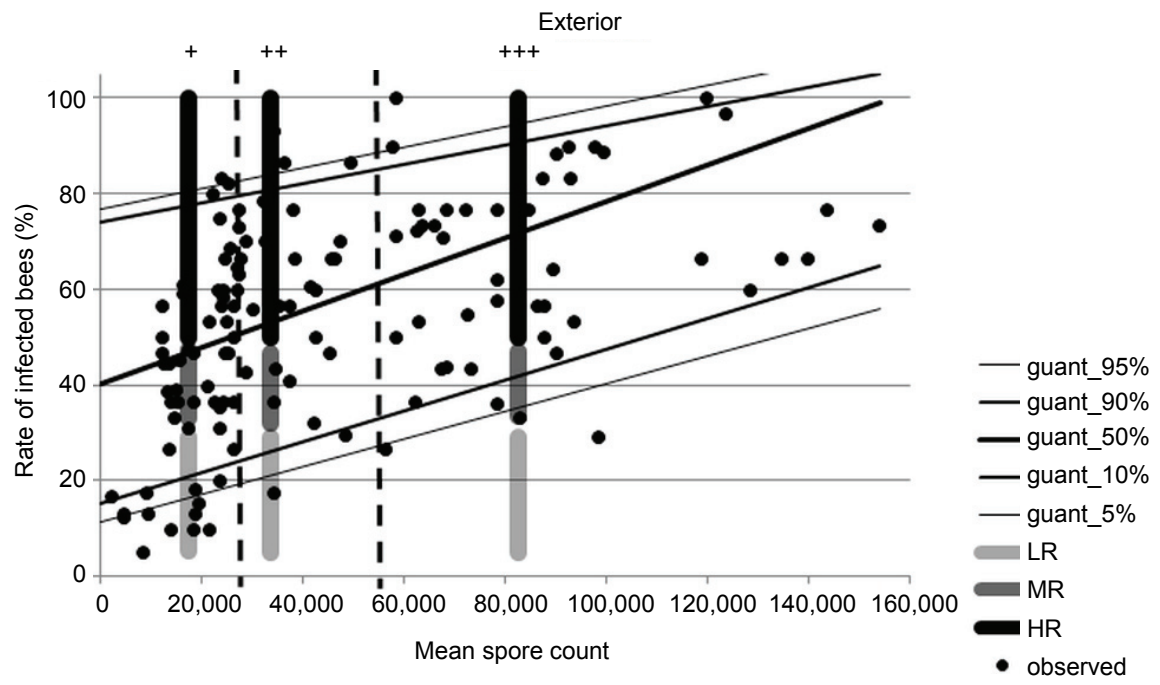

Fig. 4. Quantile regression of the rate of infected exterior bees depending on the mean spore count with the rate of spore amount $[$ low $(+)$, moderate $(++)$ and high $(+++)]$ and with the extent of infection risk [high risk (HR), moderate risk (MR) or low risk (LR)] 


\section{Historical samples}

All of the 26 available samples were visually verified to contain Nosema sp. spores using light microscopy. However, PCR methods confirmed 6 samples $(23 \%)$ only as being positive for the presence of Nosema sp. Out of these, 5 samples were co-infected and only one was confirmed to contain only $N$. ceranae.

\section{Discussion}

The results of previous and recent studies confirm that Nosema ceranae has been present in Hungary at least since 2004. The low rate of positive confirmation by PCR compared to the microscopic methods is assumed to be attributable to the storage conditions of historical samples. These samples were thawed and frozen multiple times over the years.

As an extremely low rate of infection by $N$. apis was found in each season, the theory of cyclic infection rate of $N$. apis as stated by Bailey (1955) could be revised. In contrast, $N$. ceranae is persistent. Tapaszti et al. (2009) showed that $N$. ceranae was dominant in the summer season, and data from the current study prove that it is dominant throughout the year.

Knowing that $N$. ceranae persists throughout the year, the use of treatment designed for $N$. apis may not always be appropriate. This is supported by the terminology used based on the type of infection, as Nosemosis $\mathrm{C}$ is a disease different from Nosemosis A. Previously, nosemosis was being treated when the classical disease signs appeared in early spring and late autumn. Unexpected colony weakness and losses were observed in the summer months by many beekeepers in Hungary. Since N. ceranae was not expected to be present, no treatment was applied against it. Forsgren and Fries (2010) have reported that there may not be significant differences in virulence between the two Nosema species; however, treatment against a single type may have allowed the spread of $N$. ceranae. This was confirmed in previous works by Martín-Hernández et al. (2011), Higes et al. (2013), Van der Zee et al. (2014) and Williams et al. (2014).

The results of this study also confirm the recommendation of Meana et al. (2010) that the mean proportion of infected bees may be a more reliable indicator to establish colony health. This is especially important because $N$. ceranae is a persistent issue throughout the year. Proactive monitoring for Nosema sp. by collecting exterior bees gives beekeepers a tool to better control nosemosis.

Antúnez et al. (2009) reported that the titre of vitellogenin in bees decreased after infection with Nosema sp., especially with $N$. ceranae. Nelson (2007) observed that vitellogenin titre in bees paces the onset of foraging behaviour, where the lower the titre of vitellogenin, the earlier bees mature for foraging. It may be concluded that infection with Nosema sp. lowers the titre of vitellogenin in bees, thus making the infected bees mature for foraging. If this con- 
clusion is right, it can explain why the infection rate of exterior bees is higher than that of interior bees.

Regular vortexing and centrifugation of the phenol-chloroform mixture were substituted for commercial tissue lysers and cell disrupters and biosprint for DNA extraction. The capacity was still low for analysing the numbers of samples required, but it was suitable for daily routine tests in a laboratory having modest conditions.

Study on nosemosis in Hungarian apiculture should adapt methods for collecting data on the correlation of the percentage of parasitism found and the collapse of bee colonies. Studies on N. ceranae causing mortality of bee colonies in the field or loss of honey production should be conducted (Botías et al., 2013).

\section{Acknowledgements}

This study was supported by the Consejería de Agricultura de la Junta de Comunidades de Castilla-La Mancha and the Hungarian PhD Grant System. Authors thank J. Almagro, J. García, J. M. Martínez Llana, E. Garrido Bailón, S. Rodrigo, P. Gaspar, A. Sanz, V. Albendea, A. Cepero, T. Corrales, C. Rogerio, C. Abascal, M. Anido, E. Szalainé Mátray, D. Drexler and K. Posta for their technical help and all collaborating beekeepers for letting us in their apiary and providing the bee samples.

\section{References}

Antúnez, K., Martín-Hernández, R., Prieto, L., Meana, A., Zunino, P. and Higes, M. (2009): Immune suppression in the honey bee (Apis mellifera) following infection by Nosema ceranae (Microsporidia). Environ. Microbiol. 11, 2284-2290.

Bailey, L. (1955): The epidemiology and control of Nosema disease of the honey bee. Ann. Appl. Biol. 43, 379-389.

Botías, C., Martín-Hernández, R., Barrios, L., Meana, A. and Higes, M. (2013): Nosema spp. infection and its negative effects on honey bees (Apis mellifera iberiensis) at the colony level. Vet. Res. 44, 25.

Botías, C., Martín-Hernández, R., Garrido-Bailón, E., González-Porto, A., Martínez-Salvador, A., De La Rúa, P., Meana, A. and Higes, M. (2012): The growing prevalence of Nosema ceranae in honey bees in Spain, an emerging problem for the last decade. Res. Vet. Sci. 93, $150-155$.

Cantwell, G. E. (1970): Standard methods for counting Nosema spores. Am. Bee J. 110, 222-223.

Chauzat, M. P., Higes, M., Martin-Hernandez, R., Meana, A., Cougoule, N. and Faucon, J. P. (2007): Presence of Nosema ceranae in French honey bee colonies. J. Apic. Res. 46, 127-128.

Cornman, R. S., Chen, Y. P., Schatz, M. C., Street, C., Zhao, Y., Desany, B., Egholm, M., Hutchison, S., Pettis, J. S., Lipkin, W. I. and Evans, J. D. (2009): Genomic analyses of the microsporidian Nosema ceranae, an emergent pathogen of honey bees. PLoS Pathog. 5 (6) doi: 10.1371/journal.ppat.1000466. Epub 2009 Jun 5.

Fingler, B. G., Nash, W. T. and Szabo, T. I. (1982): A comparison of two techniques for the measurement of nosema disease in honey bee colonies wintered in Alberta, Canada. Am. Bee J. 122, 369-371. 
Forsgren, E. and Fries, I. (2010): Comparative virulence of Nosema ceranae and Nosema apis in individual European honey bees. Vet. Parasitol. 170, 212-217.

Fries, I. (1997): Protozoa. In: Morse, R. A. and Flottum, K. (eds) Honey Bee Pests, Predators, and Diseases. Third edition. A. I. Root, Medina, OH. pp. 57-76.

Furgala, B. and Hyser, A. (1969): Minnesota Nosema survey. Am. Bee J. 109, 460-461.

Goblirsch, M., Zachary, Z. Y. and Spivak, M. (2013): Physiological and behavioral changes in honey bees (Apis mellifera) induced by Nosema ceranae infection. PLoS One 8, 3.

Higes, M., Martin, R. and Meana, A. (2006): Nosema ceranae, a new microsporidian parasite in honeybees in Europe. J. Invertebr. Pathol. 92, 93-95.

Higes, M., Martín-Hernández, R., Botías, C., Garrido-Bailón, E., González-Porto, A. V., Barrios, L., Jesús del Nozal, M. J., Bernal, J. L., Jiménez, J. J., García-Palencia, M. P. and Meana, A. (2008): How natural infection by Nosema ceranae causes honey bee colony collapse. Environ. Microbiol. 10, 2659-2669.

Higes, M., Meana, A., Bartolomé, C., Botías, C. and Martín-Hernández, R. (2013): Nosema ceranae (Microsporidia), a controversial 21 st century honey bee pathogen. Environ. Microbiol. Rep. 5, 17-29.

Martín-Hernández, R., Botías, C., Barrios, L., Martínez-Salvador, A., Mayack, C., Meana, A. and Higes, M. (2011): Comparison of the energetic stress associated with experimental Nosema ceranae and Nosema apis infection of honeybees (Apis mellifera). Parasitol. Res. 109, 605-612.

Martín-Hernández, R., Meana, A., Prieto, L., Salvador, A. M., Garrido-Bailon, E. and Higes, M. (2007): Outcome of colonization of Apis mellifera by Nosema ceranae. Appl. Environ. Microbiol. 73, 6331-6338.

Meana, A., Martín-Hernández, R. and Higes, M. (2010): The reliability of spore counts to diagnose Nosema ceranae infections in honey bees. J. Apicult. Res. Bee World 49, 212-214.

Nelson, C. M., Ihle, K. E., Fondrk, M. K., Page, J. E. Jr. and Amdam, G. V. (2007): The gene vitellogenin has multiple co-ordinating effects on social organization. PLoS Biol. 5, e62. doi: 10.1371/journal.pbio.0050062.

OIE (2008): Manual of Standards of Diagnostic Tests and Vaccines. http://www.oie.int/fileadmin/ Home/eng/Health_standards/tahm/2.02.04_NOSEMOSIS.pdf

Tapaszti, Zs., Forgách, P., Kővágó, Cs., Békési, L., Bakonyi, T. and Rusvai, M. (2009): First detection and dominance of Nosema ceranae in Hungarian honeybee colonies. Acta Vet. Hung. 57, 383-388.

Van der Zee, R., Gómez-Moracho, T., Pisa, L., Sagastume, S., García-Palencia, P., Maside, X., Bartolomé, C., Martín-Hernández, R. and Higes, M. (2014): Virulence and polar tube protein genetic diversity of Nosema ceranae (Microsporidia) field isolates from Northern and Southern Europe in honeybees (Apis mellifera iberiensis). PLoS One 6, 401-413.

Williams, G. R., Schutler, D., Burgher-MacLellan, K. L. and Rogers, R. E. (2014): Infrapopulation and -community dynamics of the parasites Nosema apis and Nosema ceranae, and consequences for honey bee (Apis mellifera) hosts. PLoS One 9, 1-6.

Zander, E. (1909): Tierische Parasiten als Krankenheitserreger bei der Biene. Münch. Bienenztg. 31, 196-204. 